\title{
A Novel Bottom Stirring Scheme to Improve BOF Performance through Mixing and Mass Transfer Modelling
}

\author{
Vikas SINGH, Surya Narayan LENKA, Satish Kumar AJMANI, Chaitanya BHANU and Sudhansu PATHAK \\ Tata Steel, Jamshedpur 831001, India. E-mail: vikas.singh@tatasteel.com
}

(Received on July 7, 2009; accepted on August 26, 2009)

\begin{abstract}
In combined blown basic oxygen steelmaking converter bottom stirring plays an important role in mixing within the bath. Better mixing within the bath and improved mass transfer between slag and metal is believed to cause better dephosphorisation. Normally an equal amount of gas in passed from each tuyere in bottom stirring throughout the blow. Here a novel bottom stirring scheme has been proposed and investigated where different amount of gas was injected from different tuyeres in last 3 to 5 min of the blow. The investigation was carried out with respect to mixing and mass transfer in a scaled-down physical model having appropriate similarity with the actual steelmaking vessel. The scheme, differential flow bottom stirring, basically redistributes the total bottom gas flow in a manner so that a linear flow gradient is imposed across the bath. It was found that the differential flow bottom stirring scheme gives 30-35\% improvement in mixing compared to uniform flow through all the bottom tuyeres. The scheme also gave better mass transfer rates than the conventional stirring. A $30 \%$ increase in the mass transfer rate was observed. Plant trials with the scheme were conducted to assess the impact on dephosphorisation within the practical BOF vessel. Improved BOF performance in terms of phosphorous removal was obtained in the plant trials. Comparatively lower turn-down phosphorous and improved phosphorous partition was achieved with a saving in bottom gas injection amount.
\end{abstract}

KEY WORDS: differential flow; water modelling; phosphorus partition; mixing; mass transfer; BOF performance.

\section{Introduction}

In widely practiced combined blown oxygen steelmaking converter, bottom stirring plays an important role in mixing within the bath. The additional stirring provided by the bottom agitation prevents excessive oxidation and leads to decreased oxygen content of the metal bath. Various other benefits viz. improved slag-metal interaction, increased metal yield, reduced Fe in the slag, improved dephosphorisation etc. has been realized. ${ }^{1-3)}$ All these advantages have been primarily attributed to improved hydrodynamics in the bath due to better mixing in the combined blown converters. Intense market competition and quality requirement demand further improvement in processes and products. As an example, more than $60 \%$ of the world steel production requires values less than $130 \mathrm{ppm}$ phosphorus content in the final sample. ${ }^{4)}$ The stringent demand on steel quality is continuously growing. An improvement through bottom stirring may play a major role in this context. As it is known that bath mixing is affected by parameters like how and how-much gas is injected, number of tuyeres, tuyere configuration, shape and size of the bath etc. Many investigators ${ }^{4-7)}$ have simulated the mixing conditions in top and bottom blown steelmaking processes in cold models by measuring the time required to homogenize a single phase liquid without considering the mass transfer resulting from mix- ing with the slag. Water model experiments were carried out by Paul et al. ${ }^{8)}$ to clarify the mixing and mass transfer rates of slag-metal in LD and Q-BOP furnaces by varying tuyere arrangements. They concluded that the stirring intensity of the Q-BOP process is remarkably better than that of LD process. Of all the tuyere configurations, they studied for the case of Q-BOP, a half circular tuyere arrangement was found to be the best considering all aspects of mixing, mass transfer, and bath agitation. Many studies ${ }^{8-10)}$ have shown the effect of various parameters in combined blown steel making and found that the top and bottom gas injection rate, top lance distance and the tuyere configuration are the parameters which govern the mixing and mass transfer of the bath. Das et al. ${ }^{11)}$ studied the role of dispersed gas bubbles agitation in bottom blown cold models selecting the location of the tuyeres at random to assess the effect on mixing time and found that mixing time decreases as number of basal tuyeres are increased and also stated that the plume interaction of the tuyere bubbles play an important role in deciding the change in mixing time. Matway et al. ${ }^{12)}$ showed that increasing the kinetic energy of the incoming gas at a given flow rate may cause a reduction in mass transfer rate, unless the kinetic energy gets dissipated near the liquid-liquid interface. They also found that increasing the number of tuyeres at a given total flow rate can significantly increase the mass transfer rate if gas plume coales- 
cence does not occur

The chronological change in number of the bottom tuyeres starting from a single concentric bottom tuyere to as high as eight number of bottom tuyeres has been found to enhanced mixing. In conventional practice, the flow rate among all the tuyeres was kept uniform besides optimizing total gas flow rate through them during the course of steel making. Ferro-static head and mechanical wear of the tuyere wall puts limit on the amount of gas to be injected through tuyeres. Therefore, within the limitations of operating plant and practice, an innovative concept of differential flow through bottom tuyeres has been studied. Differential flow means the flow from all the bottom tuyeres is not same during the stirring in part of the blow. A cold model study was carried out to examine the potential of various differential flow schemes in terms of mixing and mass transfer. The best differential flow scheme was tried out in the plant. The results from implementation of the scheme in the steelmaking converter have also been discussed in the later part.

\section{Methodology}

\subsection{Physical Modelling and Mixing Experimentation}

The details of the experimental set-up, parameters and procedure adapted for the cold model study has been described elsewhere. ${ }^{13)}$ The proposed and experimented differential flow bottom stirring schemes are explained here along with a brief experimental method to measure the mixing time.

The differential flow bottom stirring scheme is basically the arrangement where tuyere locations remain the same but the distribution of the flow through each tuyere was modified. Presently the existing eight bottom tuyeres are placed at about $58 \%$ of the radius of the bottom of the converter. Three different differential flow schemes (liner, V and $M$ type) as shown in Figs. 1 and $\mathbf{2}$ were tried out. In differential flow bottom stirring scheme-linear as shown in Fig. 1, the eight bottom tuyeres were divided into three zones such as lower, intermediate and highest flow and the total flow was distributed among them in the ratio of $1: 1.5: 2.5$. In each experiment the total gas flow rate was divided in the ratio of $1: 1.5: 2.5$ and injected through individual tuyere to realise the scheme. Figure 2 shows the differential flow schemes ' $\mathrm{V}$ ' and ' $\mathrm{M}$ ' types. Different flow gradient were employed to affect the mixing by changing the flow pattern in the vessel. As shown in Fig. 2(a), in differential flow scheme ' $\mathrm{V}$ ' type, flow gradient was kept highest at the sides and gradually reducing flow towards the centre. In another differential flow scheme ' $M$ ' type flow gradient has alternatively increasing and decreasing flows across the vessel as shown in Fig. 2(b).

In mixing experimentation, nitrogen gas was introduced through the top lance at a flow rate of $1200 \mathrm{lpm}$. Simultaneously nitrogen was introduced into the bath through the bottom tuyeres. The flow rate for top lance and the bottom tuyeres were maintained at a predetermined level. A tracer, $50 \mathrm{~mL}$ of $2 \mathrm{~N} \mathrm{KCl}$ solution, was injected into the bath. Thereafter the conductivity value of the bath was measured by conductivity probe with respect to time. The mixing time for each experiment was calculated from the conductivity versus time plots. Mixing time was defined as the

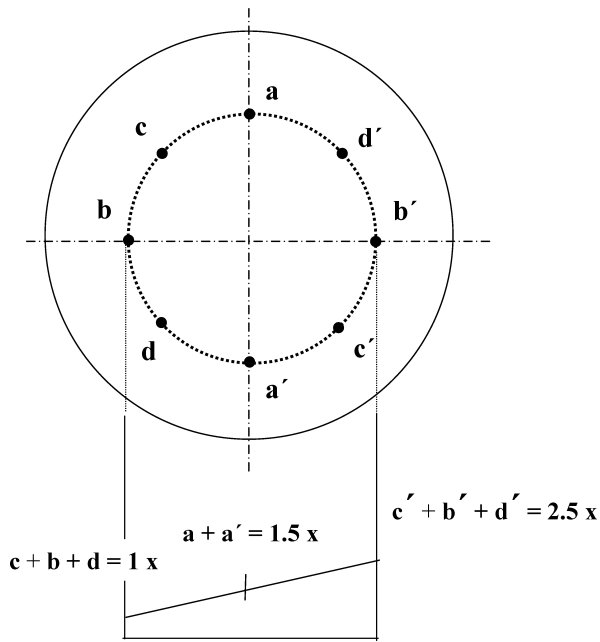

Fig. 1. Differential flow bottom stirring scheme-linear.

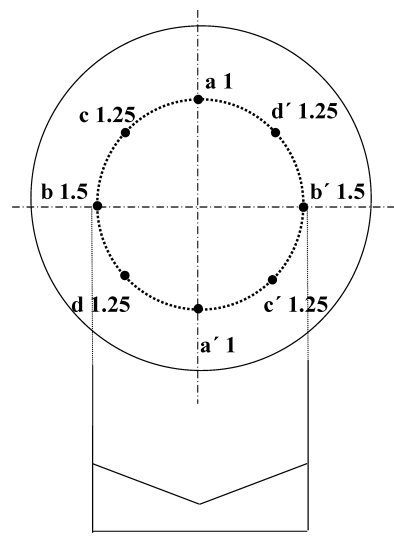

(a)

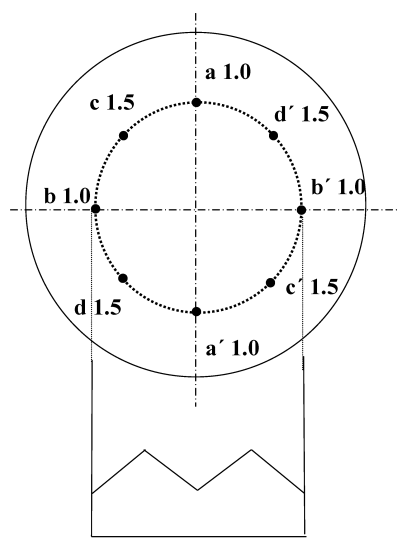

(b)
Fig. 2. Other possible differential flow schemes (a) 'V' type (b) ' $M$ ' type with their flow rate distribution.

time beyond which the changes of conductivity were less than $5 \%$ of the steady state value.

\subsection{Mass Transfer Experimentation}

To simulate the mass transfer at slag-metal interface during steel making in the converter, selection of an oil-water system was done. Water as phase-I and oil as phase-II simulates steel and slag respectively. The selection of the mass transfer system was done on basis of distribution coefficient after testing various oils. The distribution coefficient of exchange material either to phase-II or to phase-I is a measure of the extent of the transfer of the exchange material from one phase to the other. Benzoic acid was used as the exchange material for the study. The distribution coefficient can be expressed as follow:

$$
K=\frac{\text { Concentration of exchange material in phase }- \text { II after stirring }}{\text { Concentration of exchange material in phase }- \text { I after stirring }}
$$

In a typical mass transfer system selection experiment, $100 \mathrm{~mL}$ of benzoic acid solution and $100 \mathrm{~mL}$ of oil was taken and vigorously mixed for $45 \mathrm{~min}$ by a magnetic stirrer. The final concentration of the benzoic acid in water was estimated to find out the amount of benzoic acid transferred 
Table 1. Partition coefficient of the different systems tried.

\begin{tabular}{lll}
\hline Phase I & Phase II & Partition coefficient (K) \\
\hline Water & Light paraffin oil & 0.975 \\
Water & Engine oil-1 & 0.718 \\
Water & Engine oil-2 & 1.165 \\
Water & Engine oil-3 & 0.477 \\
\hline
\end{tabular}

Table 2. Physical properties of the various systems studied.

\begin{tabular}{llll}
\hline Phase I & Phase II & Density index $\left(\boldsymbol{\rho}_{\mathrm{II}} / \boldsymbol{\rho}_{\mathrm{I}}\right)$ & Viscosity index $\left(\boldsymbol{\eta}_{\mathrm{II}} / \boldsymbol{\eta}_{\mathrm{I}}\right)$ \\
\hline Water & Engine oil-1 & 0.81 & 51.1 \\
Water & Engine oil-2 & 0.84 & 75.5 \\
Water & Engine oil-3 & 0.86 & 244.4 \\
Water & Light paraffin oil & 0.85 & 35.5 \\
Steel & Slag & $0.50-0.57$ & $3-200$ \\
\hline
\end{tabular}

to oil. Distribution coefficient of exchange material was calculated by the expression given above. Water-engine oil2 system, having higher value of distribution coefficient was found to be the most suitable. Table 1 shows distribution coefficient for different mass transfer systems. The details of the mass transfer system identification are not included in this paper for sake of brevity. Density index [Density of phase-II $\left(\rho_{\mathrm{II}}\right) /$ Density of phase-I $\left.\left(\rho_{\mathrm{I}}\right)\right]$ and Viscosity index [Viscosity of phase-II $\left(\eta_{\mathrm{II}}\right) /$ Viscosity of phase-I $\left(\eta_{\mathrm{I}}\right)$ ] of the slag-metal and various mass transfer systems reviewed are enlisted in Table 2.

In a typical mass transfer experiment, benzoic acid solution of $2 \mathrm{~g} / \mathrm{L}$ was filled up in the model with $90 \mathrm{~L}$. Thereafter $18 \mathrm{~L}$ of engine oil- 2 was gently poured on it. Amount of the solution and the oil was calculated from steel to slag ratio and slag thickness as in the converters at Steelmaking Shop. Air was injected from the top lance as well as from the tuyeres at the bottom of the model vessel. Samples of phase-II i.e. oil were collected simultaneously from two points viz. liquid surface centre and $110 \mathrm{~mm}$ from the model side-wall (periphery point) of the model vessel at an interval of 2 min to ensure representative data by averaging. For each experiment same sample collection locations (centre and periphery point) were used. These samples were subsequently analyzed for their benzoic acid content volumetrically by titrating against $0.05 \mathrm{~N} \mathrm{KOH}$ solution using phenolphthalein as the indicator. To assess the transfer of benzoic acid from phase-I to phase-II, samples were collected for 20-25 min.

The mass transfer between the two fluids owing to the mixing of the phases was assumed to be of first order. The following first order rate equation was used to calculate the mass transfer rate constant $(k)^{14)}$

$$
\operatorname{Ln}\left(\frac{C_{t}-C_{\mathrm{e}}}{C_{0}-C_{\mathrm{e}}}\right)=-k t
$$

Where

$k$ : mass transfer rate constant of exchange material

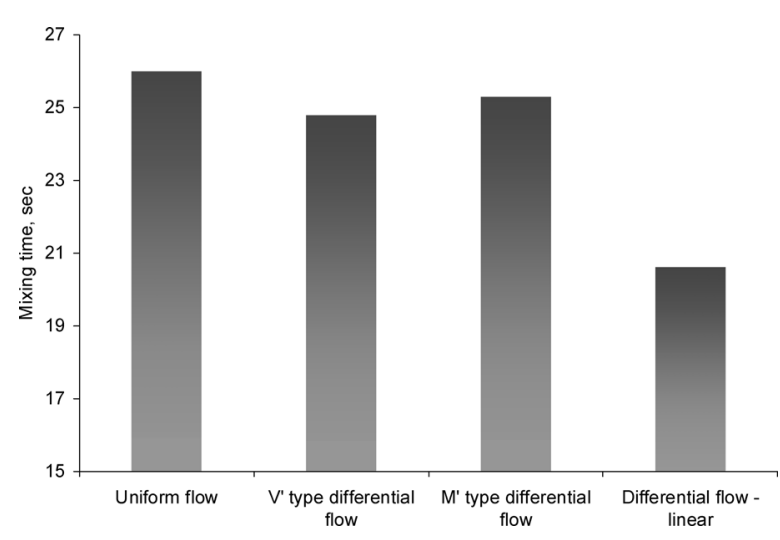

Fig. 3. Comparison of different stirring schemes for a typical flow rate of $30 \mathrm{lpm}$.

from phase-I to phase-II

$C_{\mathrm{e}}$ : equilibrium concentration of the exchange material in phase-I

$C_{t}$ : concentration of the exchange material in phase-I after time $t$

$C_{0}$ : initial concentration of exchange material in phaseI

The value of $C_{\mathrm{e}}$ in the present investigation was found to be $1.246 \mathrm{~g} / \mathrm{L}$. The value of rate constant was determined by plotting $-\ln \left[\left(C_{t}-C_{\mathrm{e}}\right) /\left(C_{0}-C_{\mathrm{e}}\right)\right]$ against time and by fitting straight lines; the slope of each line gave the value of rate constant ' $k$ '. A higher value of mass transfer rate constant indicates higher mass transfer rate from phase-I to phase-II. Therefore values of $k$ were compared for the proposed scheme.

\section{Results and Discussion}

\subsection{Effect of Differential Flow Stirring Scheme on Bath Mixing}

Mixing experiments were carried out to study the redistribution of flow among the tuyeres keeping the position of the bottom tuyeres same as it exists in one of the vessels at Tata Steel. Initially to get an idea about the various differential flow schemes proposed few experiments were carried out with each scheme at a particular flow rate. The mixing time results of various proposed differential flow schemes and comparison with base case of uniform flow is shown in Fig. 3. It can be observed from the figure that mixing time has improved with differential flow schemes ' $V$ ' and ' $M$ ' types with respect to uniform flow from each tuyere. However the improvement in mixing is less than $5 \%$ only. Whereas with differential flow bottom stirring schemelinear the improvement in mixing time is of the order of more than $30 \%$ compared to uniform flow from each tuyere. The differential flow bottom stirring scheme-linear was also found to be much better than other two differential flow schemes like ' $V$ ' and ' $M$ ' type. Hence, further investigations were carried out with the differential flow bottom stirring scheme-linear only.

A consistent improvement in mixing time was observed across the flow rates considered. The mixing results in water model showed a 30-35\% reduction in mixing time in the case of differential flow bottom stirring scheme over uniform flow through bottom tuyeres as shown in Fig. 4. 


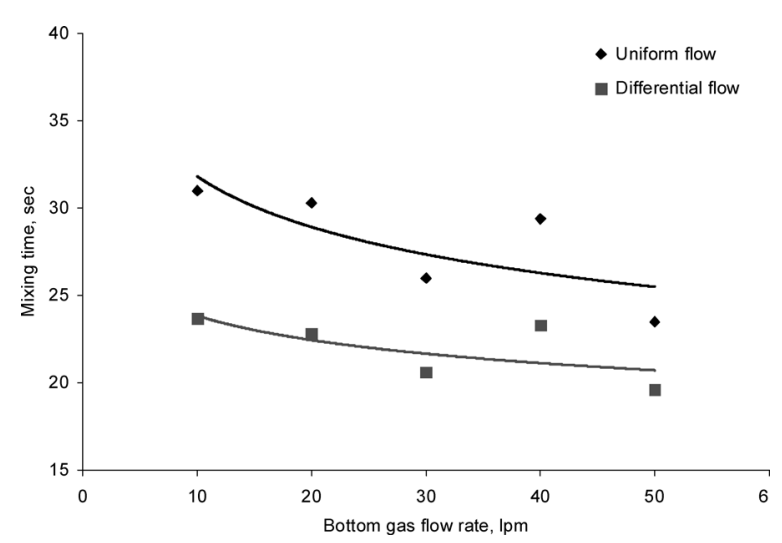

Fig. 4. Comparison of mixing time of uniform flow with differential flow.

The differential flow bottom stirring scheme-linear induces the flow energy gradient across the vessel, which in turn results in better bulk churning hence mixing in the vessel. Conventionally, the argon gas flow rate is kept equal through all the tuyeres located at the bottom of the vessel. This is like a situation where the total energy is distributed equally among the virtual cells of liquid metal surrounding each plume generated by respective gas flow through tuyeres. If a cell can be assumed like a fluid motion caused by a single gas plume, then intracellular mixing will depend upon the eddy turbulence generated at the cells interface. To have better bulk mixing within the bath the cells should interact with each other. A linear flow energy gradient across the vessel creates a favourable condition for cell to cell interaction by breaking the barrier in fluid flow caused by equal flow through all the tuyeres. In differential flow one cell may predominate over other cell to enhance interaction and thus improve bulk mixing.

\subsection{Effect on Mass Transfer}

To assess impact of the differential flow bottom stirring scheme on mass transfer rate between slag and steel, the mass transfer study was also carried out. The mass transfer rate constant was evaluated for both uniform and the differential flow. As mentioned earlier, during the mass transfer experimentation, representative samples were taken from different points in the vessel to minimise the intrinsic experimental errors. Figure 5 shows the change in concentration of benzoic acid in the water with time for differential flow condition. As mass transfer proceeds, concentration of benzoic acid decreases with time to attain equilibrium. It was observed that transfer of benzoic acid from phase-I to phase-II typically continues for about $15 \mathrm{~min}$. Figure 6 compares the outcome of mass transfer experiment for uniform and differential cases. The experimental points lying on linear portion, shown by bold, have been taken to evaluate the slope hence mass transfer rate constant. Few points have been excluded while taking the linear portion of the graph mainly at the start of experiment when mass transfer is yet to pick-up and after the steady state indicated by almost no change in concentration. An increase in mass transfer rate constant was found when differential flow was imparted through bottom tuyeres in comparison to uniform flow. The mass transfer study suggests improvement in mass transfer rate constant upto the extent of $30 \%$. The

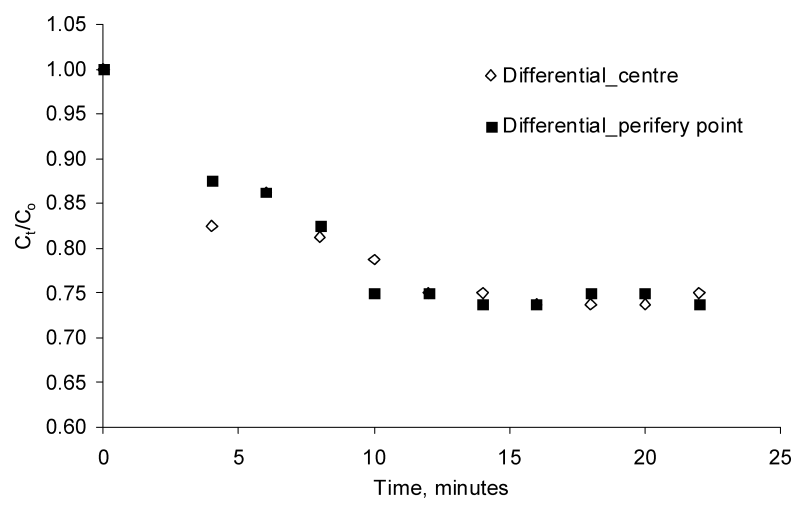

Fig. 5. A typical concentration vs. time plot for different samples points in mass transfer experimentation.

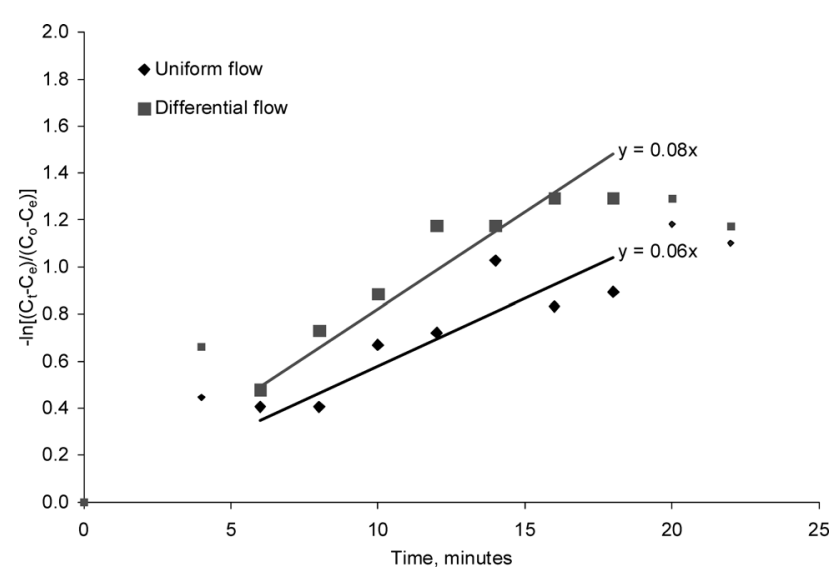

Fig. 6. Comparison of mass transfer rate constant for uniform and differential flow.

mass transfer results endorsed the mixing results achieved for the differential flow. It can be said that a better interface exchange was established between the two phases in case of the differential flow due to improved hydrodynamic of the bath. It was decided to carry out trials in the actual BOF vessel with the differential flow bottom stirring scheme.

\subsection{Plant Trials}

In general plant practice, the argon gas is passed equally through all the tuyeres located at the bottom of converter. To implement the differential flow bottom stirring scheme-linear the existing eight bottom tuyeres were virtually divided into three zones such as lower, intermediate, and highest flow and the total gas flow was distributed among them in the ratio of $1: 1.5: 2.5$ as mentioned earlier in the scheme. As shown in Fig. 1, tuyeres b, c and d were provided with individual gas flow rate of $0.4 \mathrm{Nm}^{3} / \mathrm{min}$, tuyere number a and $\mathrm{a}^{\prime}$ with individual gas flow rate of $0.9 \mathrm{Nm}^{3} / \mathrm{min}$, and tuyere number $\mathrm{b}^{\prime}, \mathrm{c}^{\prime}$ and $\mathrm{d}^{\prime}$ with individual gas flow rate of $1 \mathrm{Nm}^{3} / \mathrm{min}$.

The following guidelines were followed during the trial:

i) The gas flow rate through individual tuyere was kept between $0.4-1 \mathrm{Nm}^{3} / \mathrm{min}$ as dictated by ferro-static head and refractory erosion rate.

ii) The differential flow to come into action only when $70 \%$ of the blow of a heat was complete. The necessary changes were made in the Programmable logic controller to incorporate this. The flow rates from each tuyere after $70 \%$ of blow with uniform flow and 
differential flow bottom stirring scheme-linear are shown in Table 3. It is to be noted that lesser gas is being injected in case of differential flow.

iii) The tuyeres with higher and lower gas flow rate were interchanged after every heat in order to reduce any preferential wear of the vessel refractory.

To monitor the health of tuyeres during the trials, the vessel condition as well as back pressure in gas line was observed carefully. After each trial heat, samples were collected at turndown for chemical analysis. The results were analysed for turned-down phosphorous and actual phosphorus partition inside the converter. In turn, Phosphorous partition index (Phos partition index) and Turn-down phosphorous index (TD Phos index) were computed as:

$$
\begin{aligned}
& \text { Phos partition index }=c \cdot L_{\mathrm{p}, \text { actual }} \cdots \\
& \text { TD Phos index }=b \cdot \% \text { TD Phos } \\
& \text { actual }
\end{aligned}
$$

where $c$ and $b$ are constant.

$$
L_{\mathrm{p}, \text { actual }}=(\% \mathrm{P})_{\text {slag }} /[\% \mathrm{P}]_{\text {metal }}
$$

where $(\% \mathrm{P})$ is phosphorus in slag phase and $[\% \mathrm{P}]$ is phosphorus in the steel melt.

To assess improvement with implementation of the differential flow bottom stirring scheme-linear data were collected of 335 heats with differential flow bottom stirring scheme and 500 heats with uniform flow conditions from Steelmaking Shop No. 2 of Tata Steel. Subsequently, these data were analysed for the differential flow and compared

Table 3. Flow rates from each tuyere for uniform and differential cases.

\begin{tabular}{ccc}
\hline Tuyere & \multicolumn{2}{c}{ Bottom gas flow rate $\left(\mathbf{N m}^{3} / \mathbf{m i n}\right)$} \\
\hline Uniform flow & Differential flow \\
\hline a' & 1 & 0.9 \\
b & 1 & 0.9 \\
c & 1 & 0.4 \\
d & 1 & 0.4 \\
b' & 1 & 0.4 \\
c' & 1 & 1 \\
d' & 1 & 1 \\
\hline
\end{tabular}

with the earlier bottom stirring arrangement of uniform flow from eight tuyeres placed equi-angularly. The analysis was done with respect to extent of dephosphorisation achieved in two cases within the similar plant conditions. Analysis was carried out by using all the data available irrespective of range of turndown temperature, basicity, turndown phosphorus, phosphorus partition etc.

Figure 7 shows a box plot comparing the turndown phosphorus index and phosphorus partition index for uniform flow and differential flow. The median value of phosphorus partition index was improved by about 5 points and turn-down phosphorus index lowered from 0.017 to 0.014 as shown in the figure. A clear improvement trend was observed with complete set of the heats using differential flow. Moreover, standard deviation analysis revealed that heats with differential flow were more consistent with lower spread of data. A distribution of all the heats for turndown phosphorus index and phosphorus partition index for uniform and differential flow is shown in Fig. 8. The distribution plot also indicates better phosphorus partition in case of differential flow. A shift in peak values can be seen towards better dephosphorisation. The point to be noted here that these benefits were realised with $25 \%$ reduction in argon gas injection as differential flow requires lesser amount of total gas injection compared to normal uniform flow.

\section{Conclusion}

A novel differential flow bottom stirring scheme has been evaluated through mixing and mass transfer analysis
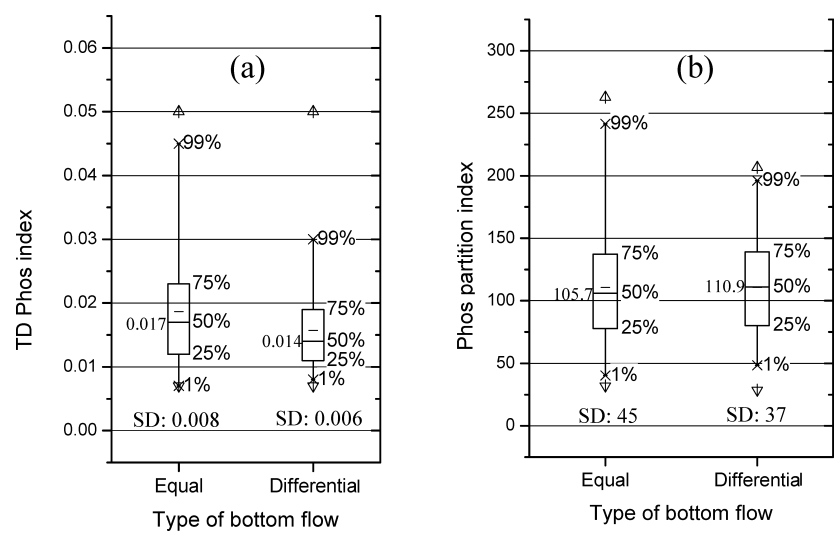

Fig. 7. Box plots showing the comparison of (a) TD Phos index (b) Phos partition index.

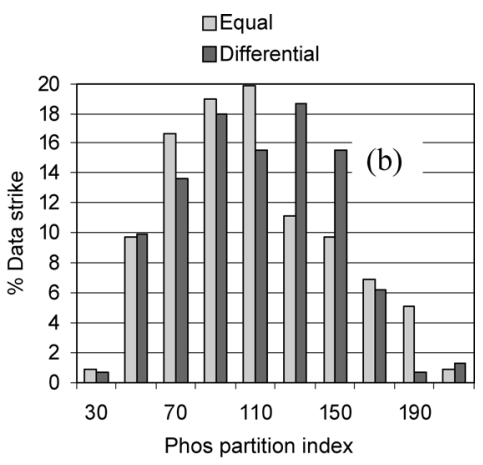

Fig. 8. Distribution plots comparing (a) Turn-down Phos index (b) Phos partition index. 
in the scale-down physical model. The scheme showed promising lab results with $30-35 \%$ reduction in mixing time in comparison to conventional uniform flow through all the bottom tuyeres and $30 \%$ enhancement in mass transfer rate between slag-metal. Plant trials with the scheme were conducted to assess the impact on dephosphorisation within the BOF vessel. The data of number of heats were analysed for turn-down phosphorous and phosphorous partition. An improved BOF performance has been observed in term of phosphorous removal with saving in bottom gas.

\section{REFERENCES}

1) A. Chatterjee, C. Marique and P. Nilles: Ironmaking Steelmaking, 11 (1984), 117

2) S. K. Choudhary and S. K. Ajmani: ISIJ Int., 46 (2006), No. 8, 1171.

3) N. Bannenberg and H. Lachmund: La Revue De Métallurgie-Cit,
July-August, (1994), 1043.

4) D. Oymo: Ph.D. Thesis, Mcgill University, Canada, (1983).

5) S. K. Ajmani and A. Chatterjee: Ironmaking Steelmaking, 23 (1996), No. 4,335 .

6) S. Ramai and A. K. Lahiri: Steel Res., 59 (1988), 193.

7) R. J. Matway, R. J. Fruhan and H. Henin: Iron Steel Maker, 16 (1989), 51.

8) S. Paul and D. N. Ghosh: Metall. Trans. B, 17B (1986), 461.

9) R. P. Singh and D. N. Ghosh: Ironmaking Steelmaking, 17 (1990), No. 5,333 .

10) S. C. Koria and S. Pal: Ironmaking Steelmaking, 17 (1990), No. 5, 325 .

11) A. K. Das, H. S. Ray and A. Chatterjee: ISIJ Int., 29 (1989), No. 4, 284.

12) R. J. Matway, R. J. Fruhan and H. Henin: Iron Steel Maker, 18 (1989), 43.

13) V. Singh, J. Kumar, C. Bhanu, S. K. Ajmani and S. K. Dash: ISIJ Int., 47 (2007), No. 11, 1605.

14) S. C. Koria: Can. Metall. Q., 31 (1992), 105. 